\title{
Non-destructive assessment of highbush blueberry fruit maturity parameters and anthocyanins by using a visible/ near infrared (vis/NIR) spectroscopy device: A preliminary approach
}

\author{
A. Ribera-Fonseca ${ }^{1,2 *}$, M. Noferini ${ }^{3}$, and A.D. Rombolá ${ }^{4}$
}

${ }^{1}$ Departamento de Producción Agropecuaria, Facultad de Ciencias Agropecuarias y Forestales, Universidad de La Frontera, Temuco, Chile. *Corresponding author: alejandra.ribera@ufrontera.cl

${ }^{2}$ Center of Plant-Soil Interaction and Natural Resources Biotechnology, Scientific and Technological Bioresources Nucleus (BIOREN-UFRO), Universidad de La Frontera, Temuco, Chile.

${ }^{3}$ FA.MO.SA SRL. (FArm MOnitoring Systems for Agriculture), 40026, Imola (Bo), Italy, email: famosasrl@gmail.com ${ }^{4}$ Dipartimento di Scienze Agrarie (DIPSA), Scuola di Agraria e Medicina Veterinaria, Alma Mater Studiorum, Università di Bologna, 40127 Bologna, Italy, email: adamo.rombola@unibo.it

\begin{abstract}
We evaluate the use of a portable and non-invasive technology based on visible and near infrared (vis/NIR) spectroscopy (Cherry-Meter) for monitoring fruit maturity parameters and anthocyanins in two highbush blueberry (Vaccinium corymbosum L.) cultivars (Misty and Sharpblue). This device measures an Index of Absorbance Difference $\left(\mathrm{I}_{\mathrm{AD}}\right)$, which showed high correlations with fruit quality parameters in other fruit crops. We found positive but differential correlations between $\mathrm{I}_{\mathrm{AD}}$ values and fruit anthocyanins, which was higher for Misty $(r=0.970, p \leq 0.01)$ than for Sharpblue $(r=0.714, p>0.05)$. Interestingly, Cherry-Meter measurements were also correlated with solid soluble concentrations $(r=0.685, p \leq 0.01)$ and fruit firmness $(r=-0.714, p \leq 0.01)$, but only in Sharpblue. For both cultivars, $\mathrm{I}_{\mathrm{AD}}$ values were also significantly $(p \leq 0.01)$ related with fruit FW $(0.447$ for Sharpblue and 0.559 for Misty). The High Performance Liquid Chromatography (HPLC) data indicated that $I_{A D}$ variations were associated with significant changes in single berry anthocyanidins levels. These findings are the first approach, highlighting the potentialities of Cherry-Meter for the non-destructive assessment of fruit maturity and anthocyanidin profile in blueberries.
\end{abstract}

Keywords: Anthocyanins, blueberry, Harvest, non-destructive, vis/NIR spectrometry 


\section{Introduction}

Worldwide highbush blueberry (Vaccinium corymbosum L.) production and consumption has significantly augmented in the recent years (Lindberg et al., 2014). The main reason for this success is the remarkable human health benefits of blueberries, including high contents of vitamins and minerals, low calories, and a noticeable antioxidant capacity for anti-aging and degenerative disease prevention (Giongo et al., 2011). The antioxidant properties of blueberries are mostly explained by its great levels of anthocyanins (Ehlenfeldt and Prior, 2001). Several agronomic and physiological factors can influence blueberry quality and phenolic content and composition (Yañez et al., 2015).

Maturity at harvest considerably determine the quality and postharvest-life potential of fruits (Kader, 1999). Fruit maturity heterogeneity difficult the estimation of the optimal harvest start date which is a concern for the fresh fruit supply chain and a crucial aspect to ensure suitable exporting procedures (Infante, 2012). Nowadays, the visual analysis of skin blue color is recognized as one of the most important maturity index used for blueberry fruits (Leiva-Valenzuela et al., 2013), which can result in inadequate homogeneity at harvest. The blue color in blueberries skin is a highly complex attribute, which is mainly function of the accumulation of anthocyanins (Ehlenfeldt and Prior, 2001), the distribution of individual anthocyanins, and the formation of metal complexes of anthocyanins (Harborne, 1976). Nonetheless, the human eye is not capable to sort accurately mature fruit deriving in a high heterogeneity of harvested fruits (Ziosi et al., 2008; Leiva-Valenzuela et al., 2013).

Few years ago, extensive research has been focused on the development of non-destructive techniques for evaluating fruit ripening (Ziosi et al., 2008; Guidetti et al. 2009; Infante et al., 2011; Bonora et al.,
2013, 2014, 2015). In this way, some technologies operating on visible and near infrared (vis/NIR) spectroscopy can allow checking in real-time the ripening progress of fruits (Bonora et al., 2013), monitoring the physiological changes of a great number of fruits with a high precision. Interestingly, reflectance-spectroscopy-based techniques have been successfully used for the detection of anthocyanins in fruits including grape clusters (Tuccio et al., 2011).

Despite the interesting advances about this topic, the use of vis/NIR spectrophotometry to non-destructively for the in-situ estimation of blueberry fruit maturity and quality has been scarcely explored (Guidetti et al., 2009). One of these devices is the Cherry-meter (DAmeter modified), an innovative and more simplified vis/NIR technology developed at the Bologna University (Bologna, Italy). This portable and userfriendly equipment provides an Index of Absorbance Difference $\left(\mathrm{I}_{\mathrm{AD}}\right)$, expressing the ripening stage of fruit, which correlates with some chemical and biochemical parameters (such as chlorophyll content and ethylene emission) to accurately describe fruit ripening (Ziosi et al., 2008; Bonora et al., 2013, 2014; Nagpala et al. 2013). The $\mathrm{I}_{\mathrm{AD}}$ has been recognized as a potential suitable harvest index to in-situ monitoring fruit maturation in some cultivars of peaches (Bonora et al., 2013, 2014, 2015), plums (Infante et al., 2011), and apples (Nyasordzi et al., 2013), among others fruit species. Lately, this device has been recently tested for the prediction of cherry maturity through the estimation of fruit skin anthocyanin, with very promising results (Nagpala et al., 2013).

The aim of this work was to study the relationship among $\mathrm{I}_{\mathrm{AD}}$ measurements and some maturity parameters and anthocyanins in blueberry fruits at harvest, in order to pre-validate the use of this device as a non-invasive tool to predict the fruit harvest date in this fruit species. 


\section{Materials and Methods}

\subsection{Experimental procedure and fruit sampling}

The study was conducted in a commercial organic farm (Agricultural Society Masseria Caporelli s.n.c., G. Mercatante \& C.) located at San Costantino Calabro (VV), Calabria Region, Italy (Latitude: $38^{\circ} 37^{\prime} 12^{\prime \prime}$ North and $16^{\circ} 15^{\prime} 47^{\prime \prime}$ East; Altitude: $450 \mathrm{~m}$ a.s.1.. Fruits samples (150 berries for each cultivar) of two highbush blueberry (Vaccinium corymbosum L.) cultivars (Sharpblue and Misty) were harvested by morning at different maturation stages near to the full maturation stage (from $100 \%$ red to $100 \%$ blue fruits) estimated visually through the fruit skin color. Berries were collected from six randomly selected bushes (five-year-old plants) per cultivar from cultivated giving a planting density of 3333 bushes per hectare at spacing ( $3.0 \mathrm{~m}$ between rows $\mathrm{x} 1.0 \mathrm{~m}$ within row). Routine horticultural management of the region was applied throughout the season in terms of pruning, irrigation fertilization and pest control. Thus, all bushes were fertilized every year with leonardite $(2000 \mathrm{~kg}$ ha $\left.{ }^{1}\right)$ applied on the soil surface in pre-harvest (March), with organic nitrogen $\left(6 \mathrm{~kg} \mathrm{ha}^{-1}\right)$ supplied by fertigation every 2 weeks and canopy-applied nitrogen $(4.25 \mathrm{~kg}$ $\left.\mathrm{ha}^{-1}\right)$, boron $\left(8 \mathrm{~g} \mathrm{ha}^{-1}\right)$ and zinc $\left(27 \mathrm{~g} \mathrm{ha}^{-1}\right)$ provided by six treatments. Pest management treatments consisted of copper $\left(0.5 \mathrm{~kg} \mathrm{ha}^{-1}\right.$, applied as oxychloride copper $)$ and mineral oil (3.3 $\left.\mathrm{kg} \mathrm{ha}^{-1}\right)$ enabling the control of fungal pathogens and cottony cushion, respectively. All fruit samples were transported and stored at $4{ }^{\circ} \mathrm{C}$ from orchard to the Vegetal Production Laboratory (Campus of Food Science, University of Bologna, Cesena, Italy), where Cherry-Meter measurements and the physical and chemical analyses were performed within the 4 days following sampling. All determinations were made on the same single fruit.

\subsection{Non-destructive analysis of fruits: Cherry-Meter data acquisition}

In order to calibrate and validate the Index of Absorbance Difference $\left(\mathrm{I}_{\mathrm{AD}}\right)$ as a non-destructive method to estimate the maturity level and quality of blueberries, Cherry-Meter (T.R. Turoni Srl., Forlí, Italy; Figure 1) was used to measure the absorbance of 30 randomly selected fresh intact fruits per cultivar, then obtaining different $\mathrm{I}_{\mathrm{AD}}$ subclasses based on the $\mathrm{I}_{\mathrm{AD}}$ value ranges (absorbance values) (Table 1). With this portable instrument, $\mathrm{I}_{\mathrm{AD}}$ values are obtained from the absorbance differences between two wavelengths associated to the sample molecules (i.e. anthocyanins; 560 and $640 \mathrm{~nm}$ ) detected in intact fruits, and the reference value at $750 \mathrm{~nm}$ (Nagpala et al., 2013). The index calculation is based in the Lambert Beer law $(\mathrm{A}=$ $\log _{10}$ I-10) (Noferini et al., 2009). This instrument consists of a light source composed of six LEDs, positioned around a photodiode: three diode LEDs emitting wavelengths of $560 \mathrm{~nm}$ and other three in length of $640 \mathrm{~nm}$. For the $\mathrm{I}_{\mathrm{AD}}$ calculation, the amount of light remitted from the fruits is captured and measured by the central photodiode, converted by an "Adc conver-ter" ("analog to digital converter") and elaborated by a micro-controller (Costa et al., 2010). The methodology and wavelengths (maximum absorbance of anthocyanins) used here were based on the previous works on cherry fruits, indicating that high $\mathrm{I}_{\mathrm{AD}}$ values obtained were related to more advanced ripening stage and higher levels of anthocyanins (Nagpala et al., 2013).

In all cases, $\mathrm{I}_{\mathrm{AD}}$ data were obtained by taking almost two measurements on the center of each fruit and reading the average value on the instrument screen. 

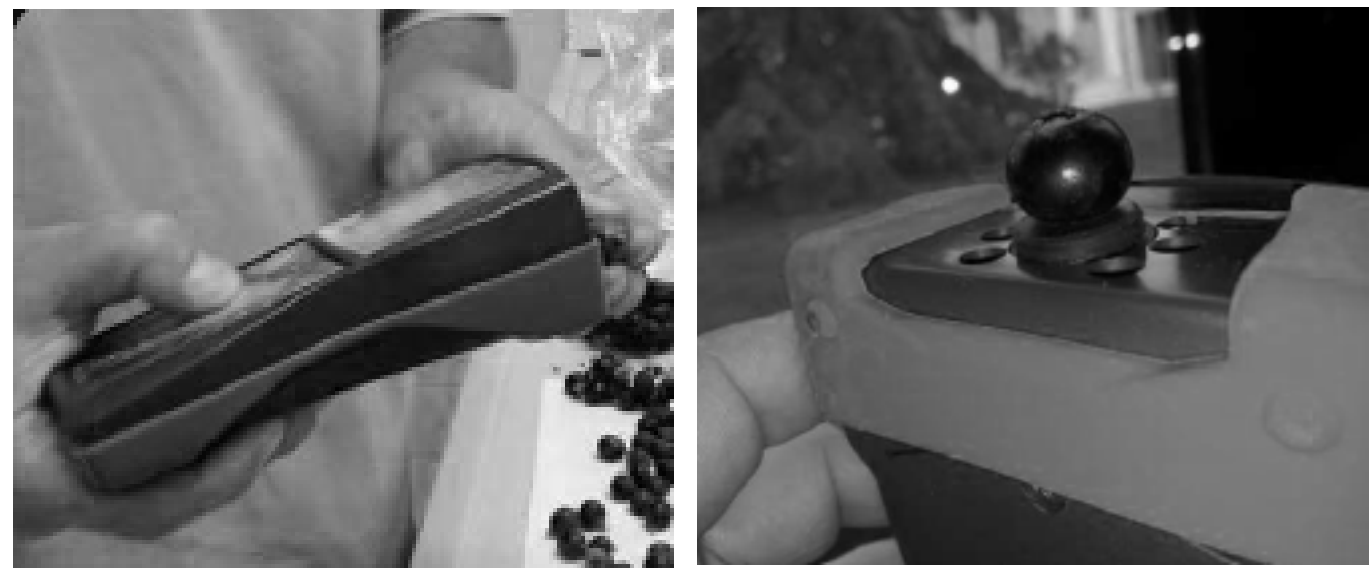

Figure 1. The Cherry-Meter device

Table 1. Range of $\mathrm{I}_{\mathrm{AD}}$ values for the different $\mathrm{I}_{\mathrm{AD}}$ sub-classes in two cultivars of highbush blueberry fruits

\begin{tabular}{|c|c|c|}
\hline \multirow{2}{*}{$\mathrm{I}_{\mathrm{AD}}$ sub-classes } & \multicolumn{2}{|c|}{$\mathrm{I}_{\mathrm{AD}}$ values } \\
\hline & cv. Sharpblue & $c v$. Misty \\
\hline SC 1 & $\leq 1.5$ & $\leq 2.0$ \\
\hline $\mathrm{SC} 2$ & $>1.5-1.7$ & $>2.0-2.2$ \\
\hline $\mathrm{SC} 3$ & $>1.7-1.9$ & $>2.2-2.4$ \\
\hline $\mathrm{SC} 4$ & $>1.9-2.1$ & $>2.4-2.6$ \\
\hline SC 5 & $>2.1-2.3$ & $>2.6-2.8$ \\
\hline SC 6 & $>2.3-2.5$ & $>2.8-3.0$ \\
\hline $\mathrm{SC} 7$ & $>2.5-2.7$ & $>3.0-3.2$ \\
\hline $\mathrm{SC} 8$ & $>2.7-2.9$ & $>3.2$ \\
\hline SC 9 & $>2.9$ & - \\
\hline
\end{tabular}




\subsection{Destructive analysis of blueberry fruits}

\subsubsection{Physical and chemical maturity parameters}

As physical quality attributes, the fruit fresh weight (FW) was determined by using an analytical balance. Total soluble solids concentration (SSC) was assessed in juices of whole fruits using a manual thermo-compensated refractometer, standardized with distilled water and expressed as Brix. In addition, Texture Profile Analysis (TPA) was used to evaluate fruit firmness parameters on a 10-berry sample. For this, before the analysis, fruit samples were exposed to room temperature $\left(20{ }^{\circ} \mathrm{C}\right)$ during $2 \mathrm{~h}$, due to commonly fruits decreasing firmness at increasing temperature (Chiabrando et al., 2009). The measurements were carried by TPA using a Texture Analyser (ZWICK ROELL mod. Z2.5TH, UK) equipped with a $5 \mathrm{~kg}$ load cell and HDP/90 platform, as previously described Chiabrando et al. (2009) for blueberry fruits. Briefly, to evaluate fruit elasticity by using TPA, the samples were deformed to $30 \%$ of the original height using a crosshead speed of 0.8 $\mathrm{mm} \mathrm{s}^{-1}$ and a $35 \mathrm{~mm}$ diameter cylinder stainless flat probe. Each sample was subjected to a two-cycle compression with $10 \mathrm{~s}$ between cycles. All these analyses were carried out in the same fruits previously evaluated through Cherry-Meter measurements.

\subsubsection{Total anthocyanin spectrophotometric determi-} nation

To obtain the anthocyanin extract, samples of $0.1 \mathrm{~g}$ of whole fruits, skin or pulp were extracted with 1 $\mathrm{mL}$ of acidified ethanol (up to $\mathrm{pH} 1$ with chlorhydric acid) in a mortar, boiled at $95{ }^{\circ} \mathrm{C}$ for $1.5 \mathrm{~min}$ for spectrophotometric analysis or $60 \mathrm{~min}$ for High Performance Liquid Chromatography (HPLC) analyses, incubated at $4{ }^{\circ} \mathrm{C}$ in the dark for 24 hours and centrifuged at $3000 \mathrm{rpm}$ for $10 \mathrm{~min}$, as described earlier by Cheng and Breen (1991). Total anthocyanin (ANTH) concentrations were estimated by the $\mathrm{pH}$ differential method as mentioned by Cheng and Breen (1991) with minor modifications Ribera et al. (2010). The absorbance of anthocyanin extracts were measured in a spectrophotometer at $530 \mathrm{~nm}$ and at 657 $\mathrm{nm}$ with a molar extinction coefficient for cyanidin3 -glucoside of 29,600. The concentrations of ANTH were expressed as milligrams of cyanidin-3-glucoside equivalent (c3g) per $100 \mathrm{~g}$ of FW. These analyses were carried out in the same fruits previously evaluated through Cherry-Meter measurements. Three different samples of 3 fruits each one were extracted.

\subsubsection{Anthocyanidin concentrations}

The anthocyanidin concentrations were evaluated by HPLC analysis using the method described by Nyman and Kumpulainen (2001) with minor modifications (Mattivi et al., 2006). Malvidin was used as standard, which was provided by Sigma. This analysis was conducted in a HPLC system (Jasco MD 1510) using a reversed-phase column RP-18, 250×4 mm $5 \mu \mathrm{m}$ ), equipped with a photodiode array detector (DAD, Jasco FP 1520). For anthocyanin extractions, samples of $0.3 \mathrm{~g}$ of whole fruits were extracted with $3 \mathrm{~mL}$ of acidified ethanol (up to $\mathrm{pH} 1$ with chlorhydric acid) using mortar and pestle. Then, $10 \mathrm{~mL}$ of the ethanolic extracts were placed into centrifugation tubes (Falcon type), which were sealed tightly and boiled at $96^{\circ} \mathrm{C}$ in a water bath for $60 \mathrm{~min}$ hour, incubated at $4{ }^{\circ} \mathrm{C}$ in the dark for 24 hours and centrifuged at $3000 \mathrm{rpm}$ for 10 min. Signals were detected in the filtrated supernatants at $530 \mathrm{~nm}$. The mobile phase was performed using acidified water [perchloric acid $\left(\mathrm{HClO}_{4}\right) \quad 0.3 \% \mathrm{v} / \mathrm{v}$ ] (A) and $100 \%$ methanol (B). The binary gradient was applied as follows: $0-39.9 \mathrm{~min}$ of $90 \% \mathrm{~A}-10 \% \mathrm{~B}$, 
40-41.9 $\min$ of $60 \% \mathrm{~A}-40 \% \mathrm{~B}, 42-48.9 \mathrm{~min}$ of $20 \% \mathrm{~A}-80 \% \mathrm{~B}$, and $49-62 \mathrm{~min}$ of $90 \% \mathrm{~A}-10 \% \mathrm{~B}$.

\subsection{Statistical analysis}

Results were assessed by one-way ANOVA using Sisvar 3.0 Software. According to the normality and homoscedasticity tests, the multiple comparison tests of means were carried out using Tukey test $(p \leq 0.05)$. Statistically different $I_{A D}$ classes were defined based on the significantly diverse anthocyanin total concentration among the $\mathrm{I}_{\mathrm{AD}}$ sub-classes. Then, with the purpose to confirm the reliability of $\mathrm{I}_{\mathrm{AD}}$ as a fruit ripening index, the correlation between $\mathrm{I}_{\mathrm{AD}}$ values with different quality and technological parameters determined destructively for each $\mathrm{I}_{\mathrm{AD}}$-classes was evaluated. The software IBM SPSS Statistics 19 was used to test the relationships between two response variables through Pearson correlations.

\section{Result and Discussion}

Here, we test a portable technique based on vis/NIR spectroscopy, measuring an Index of Absorbance Difference $\left(\mathrm{I}_{\mathrm{AD}}\right)$ (Cherry Meter), to estimate both anthocyanin concentrations and composition, and some quality parameters frequently used to assess fruit maturity and quality in blueberries.

According to our results, the statistical data analysis of the ANTH concentration of blueberries fruits from the different $I_{A D}$ sub-classes, confirmed the identification of three major $\mathrm{I}_{\mathrm{AD}}$ classes for each blueberry cultivar (Figure 2), which exhibited differential fruit SSC and FW (Table 2). Interestingly, in the present work we found that, inside the $\mathrm{I}_{\mathrm{AD}}$ sub-classes, spectroscopic data and ANTH concentrations showed significant and positive correlations, which was higher for cv. Misty ( $r=0.970, p \leq 0.01)$ compared to $c v$. Sharpblue ( $r=$
$0.714, p \leq 0.05$ ) (Table 3). Some related works have shown that non-destructive technologies based on vis/NIR spectrometry can be useful to estimate the ANTH concentration in several fruit species, including V. corymbosum (Guidetti et al., 2009), Vitis vinifera (Tuccio et al., 2011; Giovenzana et al., 2014), and Prunus avium (Nagpala et al., 2013). It is noteworthy that blueberry healthy or nutritional properties are generally determined by instrumental techniques (LC-MS; HPLC), which are time consuming, laborious and expensive. Guidetti et al. (2009) evaluated the potential of vis/NIR to analyze the nutraceutical properties of blueberry (including total anthocyanins) with interesting results. Additionally, studies reporting suitable relationships among CherryMeter measurements ( $\mathrm{I}_{\mathrm{AD}}$ values) and ANTH concentration have been previously reported by Nagpala et al. (2013) for cherry fruits. In contrast to other vis/NIR-based portable devices, CherryMeter does not require complex models that would need a continuous expensive and laborious up-date. It is important to point out that, for both cultivars, the relationship between $\mathrm{I}_{\mathrm{AD}}$ data and SSC was even lower than those detected between $\mathrm{I}_{\mathrm{AD}}$ and ANTH concentration (Table 3). Moreover, inside the $\mathrm{I}_{\mathrm{AD}}$ sub-classes, blueberries ANTH concentrations and SSC exhibited positive correlations, which was significant $(p \leq 0.05)$ for $c$. Sharpblue $(r=0.786)$ but not for cv. Misty. In grapevine berries it has been shown that the synthesis of anthocyanins is stimulated by sugars (Hiratsuka et al., 2001), mostly in the initial phase of fruit maturation when ANTH and SSC are strongly correlated. However, in the last ripening phase, the accumulation of anthocyanins and soluble solids in grapes can be uncoupled (Guidoni et al., 2008). 
These antecedents can almost partially explain our results showing that for blueberry fruits cv. Misty, blue color intensity and coverage of berry skin was not highly associated to berry SSC. This outcome could have important implications for blueberry producers and exporters.


Figure 2. Total anthocyanin (ANTH) concentration of different $I_{A D}$ sub-classes in two highbush blueberry cultivars (cv. Sharpblue and cv. Misty). The $\mathrm{I}_{\mathrm{AD}}$ values of each $\mathrm{I}_{\mathrm{AD}}$ sub-class are showed in the Table 1. Different letters indicate statistically significant differences between the $\mathrm{I}_{\mathrm{AD}}$ sub-classes according the Tukey $(p \leq 0.05)$ test. 
Table 2. Soluble solids concentration (SSC) and fresh weight (FW) of fruits from the different major $\mathrm{I}_{\mathrm{AD}}$ classes (identified on the basis of total anthocyanin concentration) in two blueberry cultivars. Different letters indicate statistically significant differences between the $\mathrm{I}_{\mathrm{AD}}$ sub-classes according the Tukey $(p \leq 0.05)$ test.

\begin{tabular}{|c|c|c|c|c|}
\hline \multirow[t]{2}{*}{ Cultivars } & \multirow[t]{2}{*}{$\mathrm{I}_{\mathrm{AD}}$ class } & \multirow{2}{*}{$\begin{array}{c}\mathrm{I}_{\mathrm{AD}} \\
\text { values }\end{array}$} & \multirow{2}{*}{$\begin{array}{l}\text { SSC } \\
\text { (Brix) }\end{array}$} & \multirow{2}{*}{$\begin{array}{l}\text { FW } \\
\text { (g) }\end{array}$} \\
\hline & & & & \\
\hline & $\mathrm{C} 1$ & $\leq 1.5$ & $08.89 \mathrm{c}$ & $0.785 \mathbf{b}$ \\
\hline \multirow[t]{4}{*}{ cv. Sharpblue } & $\mathrm{C} 2$ & $1.5-2.9$ & $11.16 \mathbf{b}$ & $0.972 \mathbf{a b}$ \\
\hline & $\mathrm{C} 3$ & $>2.9$ & $12.66 \mathrm{a}$ & $1.070 \mathrm{a}$ \\
\hline & & & $p=0.000$ & $p=0.002$ \\
\hline & $\mathrm{C} 1$ & $\leq 2.6$ & $12.09 \mathrm{a}$ & $1.467 \mathrm{~b}$ \\
\hline \multirow[t]{3}{*}{ cv. Misty } & $\mathrm{C} 2$ & $2.6-3.0$ & $12.25 \mathrm{a}$ & $1.844 \mathbf{a}$ \\
\hline & $\mathrm{C} 3$ & $>3.0$ & $12.16 \mathrm{a}$ & $1.920 \mathrm{a}$ \\
\hline & & & $p=0.981$ & $p=0.001$ \\
\hline
\end{tabular}

Table 3. Relationship among $\mathrm{I}_{\mathrm{AD}}$ values and different fruit maturity parameters in fruits of two cultivars of blueberry. SSC: soluble solid concentration; FW: fresh weight; ANTH: total anthocyanin concentration.

\begin{tabular}{lcc}
\hline Fruit & Maturity & \multicolumn{2}{c}{ Blueberry cultivars } \\
\cline { 2 - 3 } Parameters & cv. Sharpblue & cv. Misty \\
\hline ANTH & $0.714^{*}$ & $0.970^{* *}$ \\
SSC & $0.685^{* *}$ & 0.050 \\
FW & $0.447^{* *}$ & $0.559^{* *}$ \\
Hardness & $-0.713^{* *}$ & -0.350 \\
Elasticity & $-0.658^{* *}$ & 0.313 \\
\hline
\end{tabular}

Our findings also revealed that $\mathrm{I}_{\mathrm{AD}}$ values showed significant correlations with fruit $\mathrm{FW}$ in both blueberry cultivars (Table 3). In agreement with this observation, Bonora et al. (2014) found that $\mathrm{I}_{\mathrm{AD}}$ data detected by using DA-Meter device and fruit diameter were highly related in nectarines, which allowed accurate predictions of fruit yield.
Jorquera-Fontena (2015) reported that there is a strong correlation between fruit $\mathrm{FW}$ and diameter $\left(\mathrm{R}^{2}=0.99\right)$ in highbush blueberry. Therefore, further works are required in order to assess whether Cherry-Meter measurements may be useful to the in-situ estimation of fruit yield in highbush blueberry orchards. 
In accordance with previous works (Chiabrando et al., 2009), we found high fruit-to-fruit firmness variability in both blueberry cultivars. Furthermore, despite fruit TPA test did not show significant differences among $\mathrm{I}_{\mathrm{AD}}$ classes, we found that $\mathrm{I}_{\mathrm{AD}}$ values were negatively correlated with berry hardness $(\mathrm{r}=-0.714, p \leq 0.01)$ and elasticity ( $\mathrm{r}=-0.658, p \leq 0.01)$, but only for $\mathrm{cv}$. Sharpblue (Table 3 and Figure 3). Then, our TPA data allowing infer that $\mathrm{I}_{\mathrm{AD}}$ values from Cherry-Meter measurements could be useful to predict fruit firmness variations in blueberry fruits. Previous works have demonstrated that a series of fruit maturity parameters can be well predicted through vis/NIR spectroscopybased devices in blueberry. Guidetti et al. (2009) found good correlation coefficients $(r)$ between fruit absorbance values (at wavelengths ranging from 450$980 \mathrm{~nm}$ ) with ripening parameters, including SSC and firmness of fresh blueberries. To the date, related works aimed to evaluate vis/NIR spectroscopy based devices for monitoring the maturity levels of fruits did not provide information about the use of these technologies to determinate the concentration of single anthocyanidin molecules in berries. In the present work, we showed that, independently of the cultivar, the concentrations of single anthocyanidins (analysis by HPLC) significantly varied among the different $\mathrm{I}_{\mathrm{AD}}$ classes of blueberry fruits (Figure 4). In agreement with previous works (Ribera et al., 2010), we found that the anthocyanidin profile of blueberry fruits differ among cultivars, with delphinidin as the major molecule. Additionally, our data indicated that the concentration of each single anthocyanidin, including delphinidin, cyanidin, petunidin, pelargonidin, peonidin, and malvidin, increased at increasing $\mathrm{I}_{\mathrm{AD}}$ values, which was more evident in cv. Misty compared to cv. Sharpblue. In both cultivars, the concentration of petunidin and peonidin, but mainly of delphinidin, were even higher compared to the other anthocyanidins (Figure 4). Regardless of the $I_{A D}$ classes, the higher concentration of anthocyanidin molecules was detected in Sharpblue in comparison to Misty. The variation about the relationship between anthocyanidin concentration and $\mathrm{I}_{\mathrm{AD}}$ values among the single molecules can be due to the differential maximum absorbance of these compounds respect to the emission wavelengths of the CherryMeter device. It has been reported that redness and blueness of single anthocyanin molecules are directly related to hydroxylation and methylation pattern of the B ring (He et al., 2010).
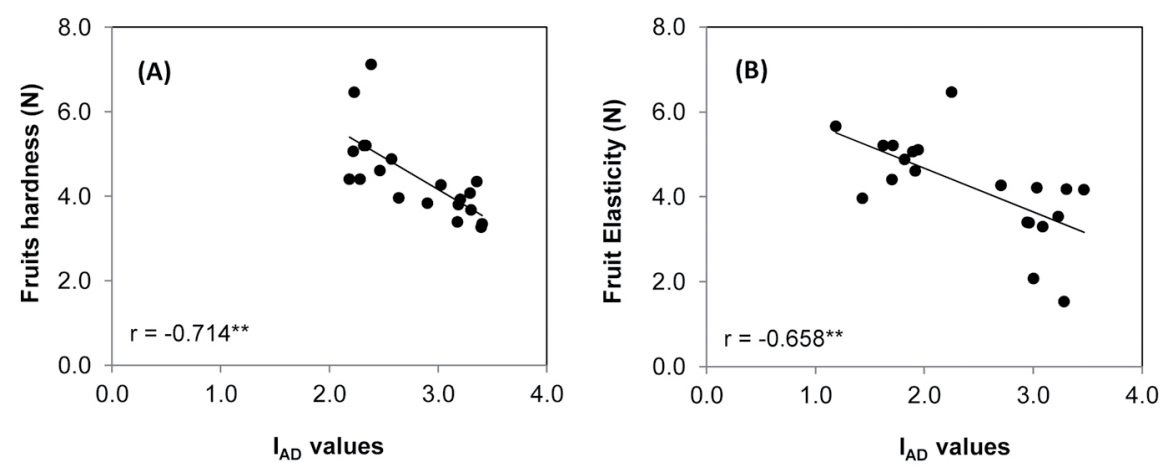

Figure 3. Fruit hardness (A) and elasticity (B) as related with $\mathrm{I}_{\mathrm{AD}}$ values in blueberries cv. Sharpblue. The Pearson correlation was used to test the relationships between the variables. Asterisks denote significance $(* * p \leq 0.01)$. 

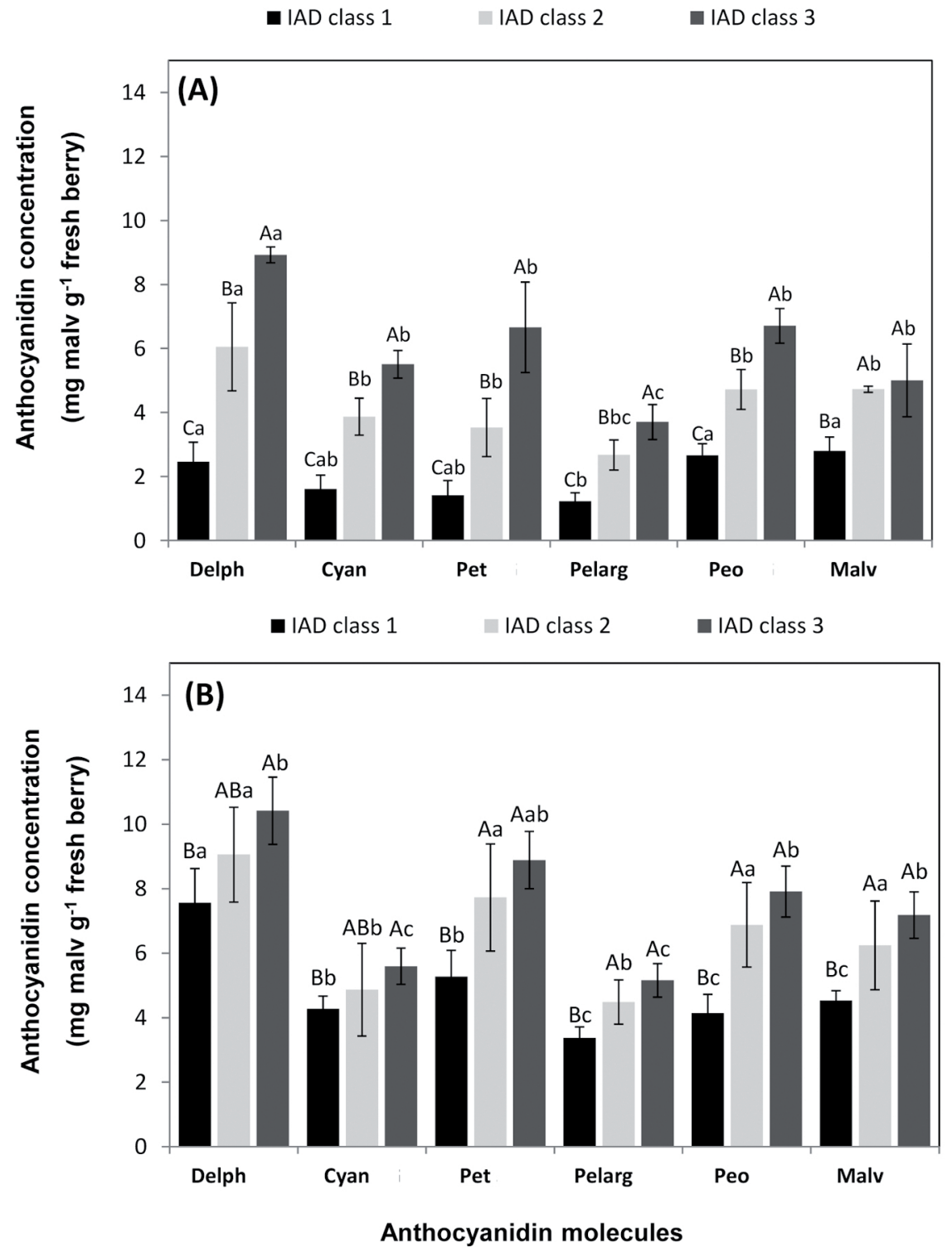

Figure 4. Anthocyanidin composition in the different $I_{A D}$ classes of blueberry fresh fruits: (A) cv. Misty and (B) cv. Sharpblue. Delph: delphinidin; Cyan: cyanidin; Pet: petunidin; Pelarg: pelargonidin; Peo: peonidin; Malv: malvidin 3-glucoside. Upper-case letters indicate significant differences among $\mathrm{I}_{\mathrm{AD}}$ classes for the same molecule, whereas lower-case letter indicate significant differences among different molecules for the same $\mathrm{I}_{\mathrm{AD}}$ class. 


\section{Conclusions}

Our data shown for the first time that the Cherry-Meter device could be considered as a potential portable instrument used to predict the maturity and health properties of blueberry fruits in a non-destructive way. When used at advanced maturation stages, Cherry-Meter was able to discriminate different maturity levels from apparently similar mature blueberry fruits. Significant correlations between Cherry-Meter measurements and fruit maturity parameters were observed, but not for both cultivars, therefore, we suggest that the calibration of the $\mathrm{I}_{\mathrm{AD}}$ values as fruit harvest and quality predictors seem to be cultivar-dependent. Interestingly, here we showed that $I_{A D}$ values offers information about the berry anthocyanidin concentration and composition, which is strongly related to the healthy/nutritional properties of this fruit. This aspect could be have a significant impact for the pharmaceutical and cosmetic industry oriented to the development of blueberry-based bioproducts as well as for further blueberry breeding programs. Further in-planta studies using these and other cultivars should be made in order to confirm and validate the large-scale functionality of this device as a reliable maturity index for blueberries selecting fruits with the biggest anthocyanin concentration, and therefore with both, a better antioxidant performance and longer shelf-life. Our results could contribute to further improve the harvest management and postharvest quality of this esteemed and healthy fruit.

\section{Acknowledgments}

The authors gratefully acknowledge the ERASMUS MUNDUS LINDO Program for the post-doc scholarship to Alejandra Ribera-Fonseca (Application code: ML13PD0997) and the Agricultural Society Masseria Caporelli s.n.c., G. Mercatante \& C., San
Costantino Calabro (VV), Calabria Region, Italy for the collaboration kindly provided.

\section{References}

Bonora, E., Stefanelli, D., Costa, G. 2013. Nectarine fruit ripening and quality assessed using the Index of Absorbance Difference $\left(\mathrm{I}_{\mathrm{AD}}\right)$. Inter. J. Agron. Article ID 242461.9 p.

Bonora, E., Noferini, M., Stefanelli, D., Costa, G. 2014. A new simple modeling approach for the early prediction of harvest date and yield in nectarines. Sci. Hort. 172, 1-9.

Bonora, E., Vidoni S., Fiori, G., Noferini, M., Kusch. C., Piccinini, L., Costa, G. 2015. A predictive model for the definition of harvest window and yield of peach fruit of the variety 'Royal Majestic ${ }^{\circledR}$. ActaHortic. 1084, 799-807.

Costa, G., Noferini, M., Bonora, E. 2010. Metodi innovativi di gestione dei frutti nella fase postraccolta - Metodi non distruttivi per valutare la qualità dei frutti. Edito da Regione Emilia-Romagna Servizio Sviluppo del Sistema Agroalimentare Assessorato Agricoltura. 200p. p.17-38- Bologna/ Italia.

Cheng, G.W., Breen, P.J. 1991. Activity of phenylalanine ammonialyase (PAL) and concentrations of anthocyanins and phenolics in developing strawberry fruit. J. Am. Soc. Hort. Sci. $116,865-869$.

Chiabrando, V., Giacalone, G., Rolle, L. 2009. Mechanical behaviour and quality traits of highbush blueberry during postharvest storage. J. Sci. Food Agric. 89, 989-992.

Ehlenfeldt, M.K., Prior, R.L. 2001. Oxygen radical absorbance capacity (ORAC) and phenolic and anthocyanin concentrations in fruit and leaf tissues of highbush blueberry. J. Agric. Food Chem. 49(5), 2222-2227. 
Giongo, L., Bozza, E., Caciagli, P., Valente, E., Pasquazzo, M.T., Pedrolli, C., Iorio, E.L., Costa, A. 2011. Short-term blueberry intake enhances biological antioxidant potential and modulates inflammation markers in overweight and obese children. J. Berry Res. 1 (3), 147-158.

Giovenzana, V., Beghi, R., Malegori, C., Civelli, R., Guidetti, R. 2014. Wavelength selection with a view to a simplified handheld optical system to estimate grape ripeness. Am. J. Enol. Vitic. 65 (1), 117-123.

Guidetti, R., Beghi, R., Spinardi, A., Mignani, I., Folin, L. 2009. Prediction of blueberry (Vaccinium corymbosum) ripeness by a portable vis-NIR device. Proc. IXth IS on Vaccinium Eds.: K.E. Hummer et al. Acta Hort. 810, ISHS.

Guidoni, S., Ferrandino, A., Novello, V. 2008. Effects of seasonal and agronomical practices on skin anthocyanin profile of Nebbiolo grapes. Am. J. Grape Wine Res. 59, 22-29.

Harborne, B. 1976. Functions of flavonoids in plants. In: Goodwin TW (Ed.). Chemistry and biochemistry of plant pigments. Academic Press, London, pp. 736-778.

He, F., Mu, L., Yan, G.L., Liang, N.N., Pan, Q.H., Wang, J., Reeves, M.J., Duan, C.Q. 2010. Biosynthesis of anthocyanins and their regulation in colored grapes. Molecules. 15, 9057-9091.

Hiratsuka, S., Onodera, H., Kawai, Y., Kubo, T., Itoh, H., Wada, R. 2001. ABA and sugar effects on anthocyanin formation in grape berry cultured in vitro. Scientia Horticulturae. 90, 121-130.

Infante, R., Contador, L., Rubio, P., Mesa, K., Meneses, C. 2011. Non-destructive monitoring of flesh softening in the black-skinned Japanese plums "Angeleno" and "Autumn beaut" on-tree and postharvest. Postharvest Biol. Tec. 61(1), 35-40.
Infante, R. 2012. Harvest maturity indicators in the stone fruit industry. Stewart Postharvest Rev. 1-6.

Jorquera-Fontena, E. 2015. Source-sinkrelationship in blueberry (Vacciunium corymbosum L.) plants: Fruit and leaf responses and a simulation model of fruit growth and sugar concetration. Doctral thesis in fulfillment of the requieriments for the degree of Doctor of Science in Natural Resources. Universidad de La Frontera, Temuco, Chile. 133 p.

Kader, A.A. 1999. Fruit maturity, ripening, and quality relationships. Acta Hort. 485, 203-208.

Leiva-Valenzuela, G.A., Lu, R., Aguilera, J.M. 2013. Prediction of firmness and soluble solids content of blueberries using hyperspectral reflectance imaging. J. Food Eng. 115, 91-98.

Lindberg, W., Hanson, E., Lobos, G. 2014. Partial inhibition of flowering in young highbush blueberries with gibberellins. Cien. Inv. Agr. 41(3), 349-356.

Mattivi, F., Guzzon, R., Vrhovsek, U., Stefanini, M., Velasco, R. 2006. Metabolite profiling of grape: flavonols and anthocyanins. J. Agric. Food Chem. 54 (20), 7692-702.

Nagpala, E.G.L., Noferini, M., Farneti, B., Piccinini, L., Costa, G. 2013. Cherry-Meter: An innovative non-destructive device for cherry fruit ripening and quality assessment. VII International Cherry Symposium, June 23-27, Plasencia, Spain.

Noferini, M., Fiori, G., Costa, G. 2009. Un nuovo índice di maturazione per stabilire la raccolta $\mathrm{Ed}$ orientare Il consumatore verso la qualità. Revista Frutticoltura. 7/8: 30-37.

Nyasordzi, J., Friedman, H., Schmilovitch, Z., Ignat, T., Weksler, A., Rot, I., Lurie, S. 2013. Utilizing the IAD index to determine internal quality attributes of apples at harvest and after storage. Postharvest Biol. Technol. 77, 80-86. 
Nyman, N.A., Kumpulainen, J.T. 2001. Determination of anthocyanidins in berries and red wine by high-performance liquid chromatography. Agric. Food Chem. 49(9), 4183-4187.

Ribera, A.E., Reyes-Díaz, M., Alberdi, M., Zuñiga, G.E., Mora, M.L. 2010. Antioxidant compounds in skin and pulp of fruits change among genotypes and maturity stages in highbush blueberry ( $\mathrm{Vac}$ cinium corymbosum L.) grown in Southern Chile. J. Plant Nutr. Soil Sci. 10(4), 509-536.

Tuccio, L., Remorini, D., Pinelli, P., Fierini, E., Tonutti, P., Scalabrelli, G., Agati, G. 2011. Rapid and non-destructive method to assess in the vineyard grape berry anthocyanins under different seasonal and water conditions. Austr. J. Grape Wine Res. 17,181-189.
Ziosi, V., Noferini, M., Fiori, G., Tadiello, A., Trainotti, L., Casadoro, G., Costa, G. 2008. A new index based on vis-spectroscopy to characterize the progression of ripening in peach fruit. Postharvest Biol. Tec. 49(3), 319-329.

Yañez-Mansilla, E., Cartes, P., Reyes-Díaz, M., Ribera-Fonseca, A., Rengel, Z., Alberdi, M. 2015. Leaf nitrogen thresholds ensuring high antioxidant features of Vaccinium corymbosum cultivars. J. Soil Sci. Plant Nutr. 15 (3), 574-586. 